\title{
A LONG-TERM EQUILIBRIUM BEACH PLANFORM MODEL FOR COASTAL WORK DESIGN
}

\author{
Verónica Cánovas ${ }^{1}$ and Raúl Medina ${ }^{1}$
}

\begin{abstract}
Traditional models usually allow fitting the equilibrium beach planform of crenulated beaches knowing wave climate characteristics at a control point. However, sometimes there are shoals or bars in the surf zone which affect surf zone dynamics and longshore sediment distribution, and it is difficult to take into account these elements using those traditional models. A long-term equilibrium beach planform model is proposed here based on sediment transport equations. This model takes into account the sediment transport due to oblique wave incidence and that due to wave height gradient. Two case studies have been studied: a simple pocket beach and a beach which is sheltered by a sandstone bar. Results show the model fits reasonably well the equilibrium beach planform to the shorelines of those beaches. This model is more suitable than traditional models when there are elements affecting surf zone dynamics.
\end{abstract}

Keywords: static equilibrium beach planform; height gradient; oblique incidence; longshore sediment transport;porous concrete; breaking wave.

\section{INTRODUCTION}

Long-term equilibrium beach planform of crenulated beaches is usually determined using the mean annual flux direction at a control point (cape, breakwater,...) and there are some models which allows fitting the equilibrium beach planform knowing these characteristics (Hsu and Evans 1989, Silvester and Hsu 1993, Tan and Chiew 1994, Gonzalez 1995,...). These models are good at determining the equilibrium beach planform in pocket beaches with simple boundaries. However, sometimes there are some geological elements near the beach which are difficult to take into account with these theoretical models (bars, shoals,...) and they are very important in the wave propagation towards the beach and consequently in the breaking wave and longshore sediment distribution.

The purpose of this work is to show an equilibrium beach planform model focused on longshore sediment transport equations proposed by Osaza and Brampton (1980), considering the parametrization proposed by Kraus and Harikai (1983) and wave series. This model take into account the wave height gradient and consequently, it can be used in pocket beaches where there are shoals, bars, etc, affecting the surf zone.

Two case studies have been studied to show how the model works: Milagro Beach and Las Canteras Beach. First one is a typical pocket beach which shoreline is easy to fit with traditional models, but Las Canteras Beach is sheltered by a sandstone beach and there are rocky areas that make difficult to fit its shoreline with traditional models. The proposed model is able to take into account the effect of the sandstone bar and the rocks on the surf zone dynamics and, consequently, it works reasonably well in both cases.

It is important to highlight that this model depends on the wave characteristics at the breaking point; therefore, the goodness of fit depends on the wave propagation model used to get those characteristics and its ability to reproduce all the processes that take place in the study area.

\section{MODEL DESCRIPTION}

The model proposed here is a long-term equilibrium beach planform model taking into account the sediment transport equilibrium after " $n$ " sea states. It is focused on the longshore sediment transport equations proposed by Osaza and Brampton (1980) considering the parameterization proposed by Kraus and Harikai (1983).Therefore, this model considers a sediment transport due to oblique wave incidence $\left(Q_{\alpha}\right)$ and another due to wave height gradient $\left(Q_{h}\right)$ which can be determined by:

$$
Q=Q_{\alpha}+Q_{h}\left\{\begin{array}{l}
Q_{\alpha}=\sum_{i=1}^{i=n}\left(H_{B_{i}}{ }^{2} C_{g_{B_{i}}}\right)\left(2 a_{1} \alpha_{B s_{i}}\right) \\
Q_{h}=-\sum_{i=1}^{i=n}\left(H_{B_{i}}{ }^{2} C_{g_{B_{i}}}\right)\left(a_{2} \frac{\partial H_{B_{i}}}{\partial y}\right)
\end{array}\right.
$$

\footnotetext{
${ }^{1}$ Environmental Hydraulics Institute "IH Cantabria", Universidad de Cantabria, c./ Isabel Torres n¹5, PCTCAN,39011,Santander, Cantabria, Spain
} 
The model makes the following assumptions:

1. The beach is in static equilibrium after " $n$ " sea states. Therefore, net sum of the longshore transport associated to these sea states must be zero.

2. All the profiles must be in equilibrium.

3. The difference between wave front angle at breaking and the shoreline direction is assumed to be small.

4. There is a sediment transport due to oblique wave incidence and another due to wave height gradient.

\section{HOW THE MODEL WORKS}

Firstly, all the input information must be collected: deep water wave data, bathymetry, beach characteristics, parameters of the littoral transport model, beach profiles where the energy fluxes will be calculated, etc.

Then, wave climate is propagated up to the breaking point with a model which considers the diffraction process as Oluca-SP wave spectral model, which is included in the Coastal Modeling System, SMC (González, 2007).

After wave propagation, the breaking wave characteristics are determined at every beach profiles for each sea state: energy flux due to breaking waves and energy flux due to wave height gradient. In this model, it has been assumed that the beach reaches a static equilibrium state and every profile is also in equilibrium. Therefore, the model is focus on solving an equilibrium energy flux system for each profile. The system can be solved like an optimization problem and the total energy flux and the perpendicular direction to the shoreline are calculated for each profile.

Finally, the equilibrium beach planform is estimated using parabolic splines which are subject to the followings conditions:

1. Initial and end point of every parabolic spline must be on a profile.

2. The equilibrium planform must be perpendicular to the normal forcing at every point.

3. Continuity condition must be fulfilled at the joints between adjacent splines.

4. First point of the equilibrium beach is known.

\section{RESULTS}

This model has been applied to Milagro Beach with is located at the North side of the Harbor of Tarragona (Spain). It is a small pocket beach which is easy to fit with traditional models because there are not elements that affect the wave propagation from control points to surf zone.

Wave climate has been obtained from the Hindcast database of Puertos del Estado (time series 1958-2001) and the outer buoy of the Autoridad Portuaria de Tarragona (2004-2007) and it has been calibrated with satellite data.

Figure 1 shows Milagro Beach planform in November 2006 and the equilibrium planform estimated by model proposed in this work.

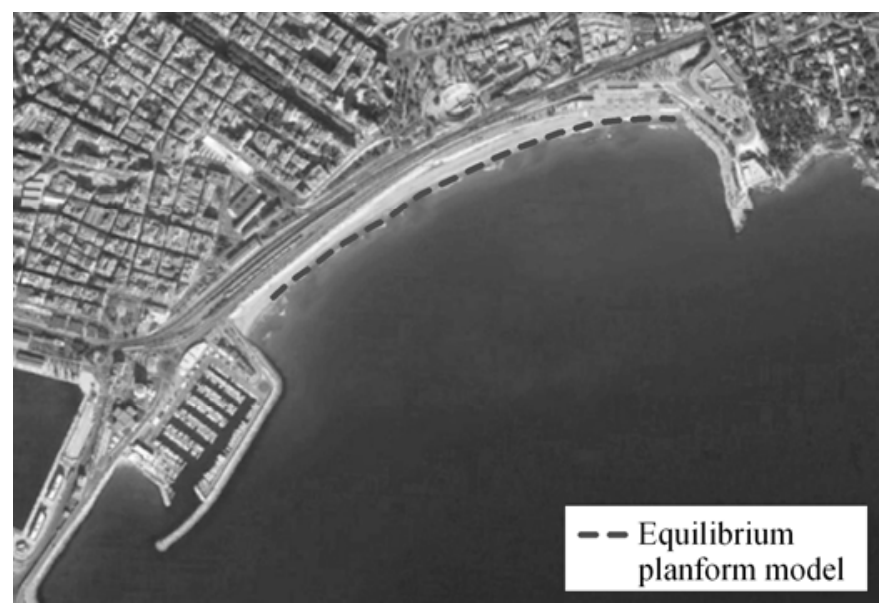

Figure 1. Milagro Beach planform in November 2006. 
In this figure, it can be seen that the proposed model fits real planform reasonably well.

Figure 2 shows Las Canteras Beach which is located at the Northwestern coast of Gran Canaria Island (Spain) and it is protected by a natural sandstone bar and there are also rocky areas which have an important influence on the surf zone dynamics.

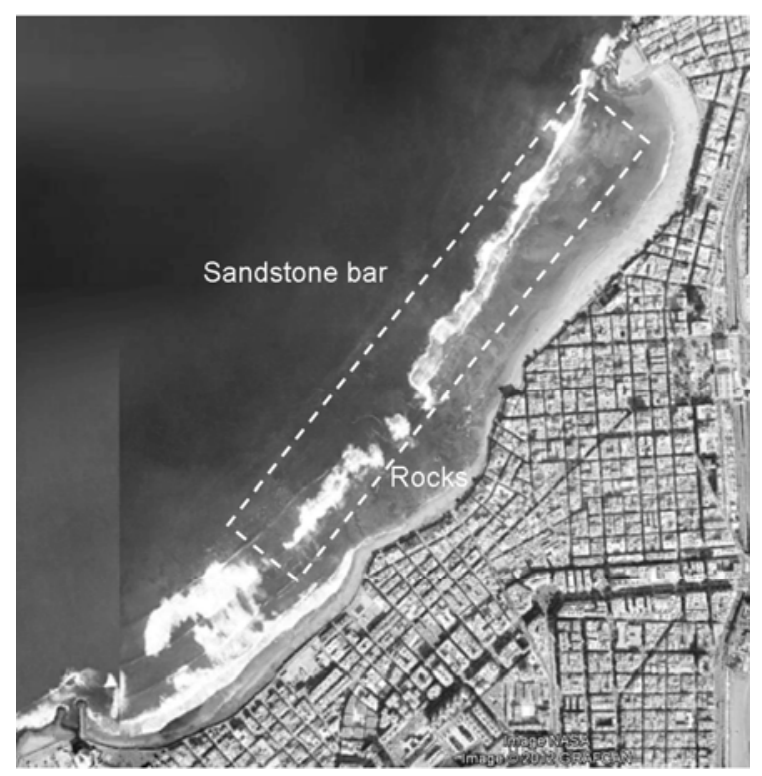

Figure 2. Las Canteras Beach.

Wave climate has been obtained from the Hindcast database of Puertos del Estado (1958-2001).

Results show that the model is able to define the shape of the equilibrium beach planform reasonably well, taking into account that there are a sandstone bar and several rocks in the surf zone. In this case, the model could not be applied to the North end of the beach because a parabolic wave propagation model was used and, therefore, results are not reliable when the incident wave turns more than $45^{\circ}$ with respect to the main wave direction.

\section{CONCLUSIONS}

A long-term equilibrium beach planform has been presented here which it is focused on wave characteristics at breaking point and it takes into account wave height gradient, therefore it works better than other equilibrium beach planform models when there are shoals or bars, affecting the surf zone.

\section{ACKNOWLEDGMENTS}

This work was partially funded by the project 'Modelado de la Evolución Morfodinámica de Playa en Medio Plazo' (CMT2008-06640), Ministry of Science and Innovation.

\section{REFERENCES}

González, M. 1995. Morfología de playas en equilibrio. Planta y perfil, Tesis doctoral, Departamento de Ciencias y Técnicas del Agua y del Medio Ambiente, Universidad de Cantabria, 270 pp.

González, M., R. Medina, J. González-Ondina, A.F. Osorio, F.J. Méndez, and E. García. 2007. An integrated Coastal Modeling System for analyzing Beach processes and beach restoration projects, SMC, Computers \& Geosciences, 33 (7), 916-931.

Hsu, J.R.C, and C. Evans. 1989. Parabolic bay shapes and applications, Institution of Civil Engineers Proceedings, ICE, 556-570.

Kraus, N.C. and S. Harikai. 1983. Numerical model of the shoreline change at Oarai beach, Coastal Engineering, 7, 1-28.

Ozasa, H. and A.H. Brampton. 1980. Mathematical modeling of beaches backed by seawalls, Coastal Engineering, 4, 47-63. 
Silvester, R. and J.R.C. Hsu. 1993. Coastal Stabilization: Innovative Concepts, Prentice-Hall, Englewood Cliffs, New Jersey, 578 pp.

Tan, S. and Y. Chiew. 1994. Analysis of bayed beaches in static equilibrium, Journal of Waterway, Port, Coastal, and Ocean Engineering, 120 (2), 145-153. 